\title{
Effect of static magnetic field pretreatment on growth, photosynthetic performance and yield of soybean under water stress
}

\author{
L. BAGHEL, S. KATARIA ${ }^{+}$, and K.N. GURUPRASAD \\ School of Life Sciences, Devi Ahilya University, Khandwa Road, Indore (M.P.), India
}

\begin{abstract}
In order to evaluate the effect of static magnetic field (SMF) on morphological and physiological responses of soybean to water stress, plants were grown under well-watered (WW) and water-stress (WS) conditions. The adverse effects of WS given at different growth stages was found on growth, yield, and various physiological attributes, but WS at the flowering stage severely decreased all of above parameters in soybean. The result indicated that SMF pretreatment to the seeds significantly increased the plant growth attributes, biomass accumulation, and photosynthetic performance under both WW and WS conditions. Chlorophyll $a$ fluorescence transient from SMF-treated plants gave a higher fluorescence yield at J-I-P phase. Photosynthetic pigments, efficiency of PSII, performance index based on absorption of light energy, photosynthesis, and nitrate reductase activity were also higher in plants emerged from SMF-pretreated seeds which resulted in an improved yield of soybean. Thus SMF pretreatment mitigated the adverse effects of water stress in soybean.
\end{abstract}

Additional key words: carbon metabolism; dry mass; magneto-priming; nitrogen metabolism; PSII efficiency.

\section{Introduction}

In persistently changing environment, there are many adverse stress conditions, such as cold, drought, salinity, and UV-B, which influence plant growth and crop production greatly (Shao et al. 2007). Drought is a worldwide problem that seriously affects crop production and quality (Passioura 2007). Water deficiency has a profound impact on ecological and agricultural systems and is a limiting factor in the initial phase of plant growth and establishment (Shao et al. 2009). Water deficit at certain times of the growing season can be compensated after rewatering so that crop growth and yield are sustained (Shan and Zhang 2006).

Under stress conditions, the plants present a series of changes in their morphology, physiology, and biochemistry, negatively affecting their growth and productivity. In various parts of the world, the impacts of water stress on crop plants can reduce productivity by $50 \%$ (Lisar et al. 2012). According to Gerten and Rost (2010), twothirds of world food production through cultivation occurs under water stress. The stress induced by water deficits in plants depends on the conditions provided by the environment, varying according to the intensity and duration of water deficits, the rate of water-deficit induction, and the stage of plant development when drought occurs (Pinheiro and Chaves 2011, Bertolli et al. 2012).

Magneto-priming is one of the techniques of modern agronomic practices to improve seed vigour, growth, and yield of plants; it is an efficient and eco-friendly technology based on physical treatments of seeds. SMF is an inevitable environmental factor for plants on the Earth. In several plant species, the speed of germination and seedling growth increases by pre-germination exposure of the dry seed to an introduced magnetic field (Shine et al. 2011, Krawiec et al. 2013, Mahajan and Pandey 2014). Several previous studies also demonstrated that SMF pretreatment could alleviate the harmful effect of other stresses, such as heat (Ružič and Jerman 2002), cadmium (Chen et al. 2011), and salinity (Thomas et al. 2013, Baghel et al. 2016).

Climate change results in increased drought stress

Received 10 October 2016, accepted 16 February 2017, published as online-first 3 April 2017.

${ }^{+}$Corresponding author; e-mail: sunita_kataria@yahoo.com

Abbreviations: Car - carotenoids; Chl - chlorophyll; DAE - days after emergence; DM - dry mass; FS - flowering stage; PI ${ }_{a b s}-$ performance index based on absorption of light energy; $P_{\mathrm{N}}$ - net photosynthetic rate; PFS - pod-filling stage; PLS - pod lengthening; ROS - reactive oxygen species; SMF - static magnetic field; UT - untreated seeds; VS - vegetative stage; WW - well watered; WS water stress.

Acknowledgements: UGC Rajiv Gandhi National Fellowship (F1-17.1/2013-14/RGNF-2013-14-ST-MAD-53993/ (SAIII/Website) to L. Baghel and Department of Science and Technology, Women Scientists Scheme - A (SR/WOS-A/LS-674/2012-G) to S. Kataria. 
and water scarcity is already the abiotic stress most limiting crop production (Wallace 2000); it is particularly pertinent to the drought-sensitive legumes (Liu et al. 2005). For example, a moderate level of water deficit can reduce soybean production by approximately $40 \%$ (Manavalan et al. 2009), thus limiting the production of soybean vegetable oil, protein feed or biodiesel (Friedman and Brandon 2001). Soybean production generally depends on natural rainfall, but uneven distribution of rainfall (too much or too little) causes year-to-year yield variation in the same field. Soybean (Glycine max L. Merrill) has excelled as a major oilseed crop. It is one of the major crops of the world meeting half the global

\section{Materials and methods}

Plant material: The seeds of soybean (Glycine max L. Merrill cv. JS 335) were obtained from the Directorate of Soybean Research, Indore, India. The experiments were conducted on the terrace of Department of Life Sciences, Devi Ahilya University, Indore, India (latitude $22^{\circ} 43^{\prime} \mathrm{N}$ ) during August - November 2015. The SMF-treated and untreated moistened seeds of soybean var. JS-335 were also treated with recommended fungicides, i.e., Bevistin and Diathane $M$ at $2 \mathrm{mg} \mathrm{kg}^{-1}$ (seed), and then the seeds were inoculated with powder of Rhizobium culture (National Fertilizer Limited, New-Delhi, India) with $3 \mathrm{~g}$ $\mathrm{kg}^{-1}$ (seed) before sowing. The Rhizobium ( $R$. japonicum) culture was sprinkled well to the moistened soybean seeds so that all the seeds were properly coated with it. The seeds of uniform size and shape were sown in plastic nursery bags $(34 \times 34 \mathrm{~cm})$ filled with a mixture of thoroughly sieved soil, sand, and farm-yard manure in the proportion of $2: 2: 1$ by volume. Five plants of uniform size were maintained in each bag.

Magnetic field pretreatment to seeds: An electromagnetic field generator Testron EM-20 (Testron Instruments, Delhi, India) with variable horizontal magnetic field strength (50-500 mT) with a gap of $5 \mathrm{~cm}$ between pole pieces was fabricated (Vashisth and Nagarajan 2008). The pole pieces were cylindrical in shape with $9 \mathrm{~cm}$ in diameter and $16 \mathrm{~cm}$ of length. The number of turns per coil was 3,000 and the resistance of the coil was $16 \mathrm{Ohm}$. A direct current (DC) power supply (80 V/10 A) with continuous variable output current was used for the electromagnet. A digital Gauss meter model DGM-30 (Testron Instruments, Delhi, India) operating on the principle of Hall effect monitored the field strength produced in the pole gap. The probe made up of indium arsenide crystal encapsulated by nonmagnetic sheet of $5 \times 4 \times 1 \mathrm{~mm}$; this probe can measure SMF from 0-2 T with a full scale range in increments of $5 \mathrm{mT}$.

Soybean seeds were exposed to a SMF of $200 \mathrm{mT}$ (for $1 \mathrm{~h}$ ) in a cylindrical-shaped sample holder of $42 \mathrm{~cm}^{3}$ capacity, made from a nonmagnetic thin transparent plastic demand for vegetable oils and proteins. Keeping in mind the significant effect of SMF treatment, the objective of the present study was to examine whether the pretreatment of seeds with SMF could alleviate the adverse effects of water stress on growth, various physiological attributes, and yield in soybean plants. No information is available in this respect for soybean under water stress. To the best of our knowledge this is the first study on the SMF effects on growth, dry mass accumulation, photosynthesis together with chlorophyll $(\mathrm{Chl})$ fluorescence-related parameters and yield in soybean under water stress given at different growth stages.

sheet. For SMF treatment, hundred apparently healthy seeds held in the plastic container were placed between the poles of the electromagnet under a uniform magnetic field. By regulating the current in the coils of the electromagnet, the required strength of the magnetic field was obtained. A Gauss meter was used to measure the strength of the magnetic field between the poles. At low field $(50 \mathrm{mT})$, from centre to end of the poles, the variation was $0.6 \%$ in the horizontal direction and $1.6 \%$ in the vertical direction of the applied field. At high field (500 mT), they were 0.4 and $1.2 \%$ of the applied field, respectively. The local geomagnetic field was less than $6 \mathrm{mT}$. Treatment by $200 \mathrm{mT}$ (for $1 \mathrm{~h}$ ) was found to be the most beneficial dose of SMF for improving physiological characteristics in soybean (Shine et al. 2011) under normal ambient conditions, so in the present study we used such a treatment for soybean seeds under drought stress. All treatments were run simultaneously along with control under similar conditions.

Effect of SMF pretreatment of soybean seeds under water stress (WS) under field conditions: The irrigation was ceased during four stages, such as vegetative, reproductive, grain filling, and maturity stage. The climate was characterized by a mean yearly air temperature of $25^{\circ} \mathrm{C}$ and a total annual rainfall of $1,062 \mathrm{~mm}$. During the study period the mean air temperature was $24.5^{\circ} \mathrm{C}$, total rainfall was $605 \mathrm{~mm}$.

\begin{tabular}{llll}
\hline Stage & & DAE & Time of stress aplication \\
\hline VS & Vegetative & 30 & Four fully expanded leaves \\
FS & Reproductive & 40 & At the beginning of flowering \\
PLS & Grain filling & 50 & The first pod appeared \\
PFS & Maturity & 60 & The seed formation started \\
\hline
\end{tabular}

For all these stages, the irrigation was stopped for $5 \mathrm{~d}$. Then the plants were rewatered untill their maturity. Another group of control plants was watered daily and termed as well-watered plants (WW). 
Plant growth: All growth attributes were measured in plants emerged from SMF (200 mT for $1 \mathrm{~h}$ )-pretreated and untreated seeds (UT) under WW and WS conditions at different stages of their development. The aboveground growth attributes of soybean, such as plant height and leaf area, were measured at VS, FS, PLS, and PFS. The plants were removed from the plastic nursery bags along with the soil and adhering soil particles were gently removed. Plant height was measured from the soil to shoot tip level. The area of third trifoliate leaf was measured using portable laser leaf area meter CID 202 scanning planimeter (CID Bio-Science, NW Camas, WA).

The belowground growth attributes of soybean, such as root length and root dry mass (DM) per plant, were taken at VS, FS, PLS, and PFS. Roots were taken out carefully, washed, and the root length was measured. For root DM, plant roots with nodules were dried at $60^{\circ} \mathrm{C}$ for $72 \mathrm{~h}$ and weighed.

Pigment content: Photosynthetic pigments were extracted by dimethyl sulfoxide (DMSO) (Merck, Mumbai, India) (Hiscox and Israelstam 1979) from the third trifoliate leaves of 30 and 40-d-old soybean plants emerged from SMF and UT seeds under WW and WS conditions (at VS and FS on 30 and 40 DAE, respectively). For the extraction of Chl and carotenoids (Car), $25 \mathrm{mg}$ well-cleaned fresh leaf discs were transferred in to a test tube containing $10 \mathrm{ml}$ of DMSO. The contents were incubated at $65^{\circ} \mathrm{C}$ for $3 \mathrm{~h}$ and volume was made up to $10 \mathrm{ml}$ with DMSO. The content was allowed to settle down and the absorbance was measured at 470, 649, and $665 \mathrm{~nm}$ with Shimadzu UV/VIS 1601 spectrophotometer (Kyoto, Japan). Equations of Wellburn and Lichtenthaler (1984) were used to calculate the $\mathrm{Chl} a$, Chl $b$, total Chl, and Car concentrations. Chl content was expressed as $\mathrm{mg} \mathrm{g}^{-1}$ (leaf FM). The analysis of pigments was done in triplicates; five leaves from each replicate were taken for the extraction of the pigments.

Chl $\boldsymbol{a}$ fluorescence transient exhibited by dark-adapted (30 min) leaves was measured by a Handy PEA fluorimeter (Hansatech Instruments, Pentney, King's Lynn, UK) in the third trifoliate leaves of 30 and 40-d-old soybean plants that emerged from SMF (200 mT for $1 \mathrm{~h}$ )-pretreated and UT seeds under WW and WS conditions (at VS and FS on 30 and 40 DAE, respectively). The transients were induced by red light (peak at $650 \mathrm{~nm}$ ) of $600 \mathrm{~W} \mathrm{~m}^{-2}(3,200 \mu \mathrm{E}$ $\mathrm{m}^{-2} \mathrm{~s}^{-1}$ ) provided by an array of six light emitting diodes, focused on the leaf surface in the clips on a spot of $4 \mathrm{~mm}$ diameter to provide homogenous illumination over the exposed area of the sample. Data were recorded for $1 \mathrm{~s}$ with 12 bit resolution; the data acquisition was every $10 \mu \mathrm{s}$ for the first $2 \mathrm{~ms}$ and every $1 \mathrm{~ms}$ thereafter (Strasser et al. 1995). All the measurements were recorded at $25 \pm 1^{\circ} \mathrm{C}$. The Chl $a$ fluorescent transient, when plotted on a logarithmic scale clearly showed a polyphasic fluorescence rise kinetics (O-J-I-P phase). The fluorescence intensity at $20 \mu \mathrm{s}$ was considered as the intensity $F_{o}$
(O phase) when all reaction centers are open, the fluorescence intensity at $2 \mathrm{~ms}$ was $\mathrm{J}$ phase, $30 \mathrm{~ms}$ was I phase, and the maximum fluorescence $\left(F_{m}\right)$ was the $P$ phase. $\left(F_{p}\right.$ equals here to $F_{m}$ since the excitation intensity is high enough to ensure the closure of all reaction centers of PSII).

We calculated the quantum efficiencies, such as maximum quantum yield of PSII photochemistry $\left(\mathrm{F}_{\mathrm{v}} / \mathrm{F}_{\mathrm{m}}\right)$, which is equal to the efficiency by which absorbed photon will be trapped by the PSII reaction center with the resultant reduction of $\mathrm{Q}_{\mathrm{A}}$ to $\mathrm{Q}_{\mathrm{A}}{ }^{-}\left(\mathrm{TR}_{\mathrm{o}} / \mathrm{ABS}\right)$, phenomenological fluxes, such as electron transport per leaf $\mathrm{CS}$ $\left(\mathrm{ET}_{\mathrm{o}} / \mathrm{CS}_{\mathrm{m}}\right)$, and the performance index based on absorption of light energy $\left(\mathrm{PI}_{\mathrm{abs}}\right)$. All of these parameters were measured using the software Biolyzer HP 3 (Chl fluorescence analyzing program by Bioenergetics Laboratory, University of Geneva, Switzerland).

Leaf gas exchange: Gas-exchange parameters, i.e., $\mathrm{CO}_{2}$ assimilation $\left(P_{\mathrm{N}}\right)$, intracellular $\mathrm{CO}_{2}$ concentration $\left(C_{\mathrm{i}}\right)$, stomatal conductance $\left(g_{\mathrm{s}}\right)$, and rate of transpiration $(E)$ were recorded in each treatment by using a portable infra red gas analyzer (LI-6200, LICOR, Lincoln, Nebraska) on third trifoliate leaves of intact plants that emerged from SMF (200 mT for $1 \mathrm{~h}$ )-pretreated and UT seeds under WW and WS conditions (at VS and FS on 30 and 40 DAE, respectively) at midday between 11:00 and 12:00 h. The gas-exchange estimations were measured on the same leaves for which $\mathrm{O}-\mathrm{J}-\mathrm{I}-\mathrm{P}$ test parameters were calculated. Photosynthetic measurements were made under ambient temperature and $\mathrm{CO}_{2}$ concentration on clear days in each

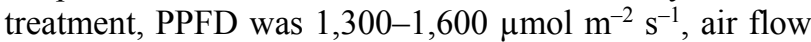
of $500 \mu \mathrm{mol} \mathrm{s}^{-1}$, and $\mathrm{CO}_{2}$ concentration of $350-380 \mathrm{ppm}$.

Nitrate reductase (NR) activity and crop yield: Nitrate reductase (EC 1.6.6.1) activity was determined by the intact tissue assay method of Jaworski (1971) in the third trifoliate leaves of soybean plants emerged from SMF (200 mT for $1 \mathrm{~h}$ )-pretreated and UT seeds under WW and WS conditions (at VS and FS on 30 and 40 DAE, respectively). Chopped leaf pieces $(100 \mathrm{mg})$ were incubated for $2 \mathrm{~h}$ at $30^{\circ} \mathrm{C}$ in a $10 \mathrm{ml}$ of reaction mixture, which contained $2.5 \mathrm{ml}$ of $0.1 \mathrm{M}$ phosphate buffer, $0.5 \mathrm{ml}$ of 0.2 M potassium nitrate, and $2.5 \mathrm{ml}$ of 5\% isopropanol (Merck, Mumbai, India). The nitrite formed subsequently was determined at $540 \mathrm{~nm}$ after azocoupling with sulphanilamide (HiMedia, Mumbai, India) and naphthylenediamine dihydrochloride (Sigma Aldrich, Mumbai, India). The NR activity was expressed as $\mathrm{nM}\left(\mathrm{NO}_{2}\right) \mathrm{g}^{-1}(\mathrm{FM}) \mathrm{h}^{-1}$.

All yield attributes were measured at harvest maturity (120 DAE) of soybean plants emerged from SMF (200 mT for $1 \mathrm{~h}$ )-pretreated and UT seeds under WW and WS conditions at VS, FS, PLS, PDS at 30, 40, 50, and 60 DAE, respectively. Yield attributes including total dry mass (DM) accumulation, number of pods per plant, seed mass per plant, and 100-seed mass were taken at the crop maturity in three replicates of five plants each. 
Statistical analysis: All the data are presented in triplicates $(n=3)$, five plants from each replica were taken for the recording of all parameters studied. The data are

\section{Results}

Growth and DM: All the aboveground and belowground growth attributes of soybean were measured at different stages of WS and under WW conditions. Pre-sowing treatment with SMF was effective in improving all the measured aboveground and belowground growth parameters in both WW and WS conditions.

The severe reduction in aboveground and belowground growth attributes was found when WS was given at FS (40 DAE) as compared with WW (Fig. $1 A-C$ ) in the plants emerged from UT seeds. It caused $51 \%$ reduction in plant height and $38 \%$ reduction in leaf area as compared with WW conditions in plants, which emerged from UT seeds (Fig. 1A,B), while the plants that emerged from SMFpretreated seeds showed an enhancement in all these parameters as compared with UT seeds at different stages and WS. Plant height was enhanced by $49,36,78$, and $51 \%$ at VS, FS, PLS, and PFS, respectively, by SMF as compared with UT seeds (Fig. 1A). Leaf area was enhanced by $31,42,53$, and $50 \%$ at VS, FS, PLS, and PFS, respectively (Fig. 1B).

Belowground growth attributes, i.e., root length and root DM, also decreased in plants emerged from UT seeds expressed as means $\pm \mathrm{SE}$ and analyzed by the Student's $t$-test by using Microsoft Excel.

under WS conditions at all the stages VS, FS, PLS, and PFS as compared with WW conditions. The significant reduction of $25 \%$ in root length and $32 \%$ in root DM was found when WS was given at FS stage as compared with WW conditions in the plants emerged from UT seeds (Fig. 1C,D), while SMF treatment increased both the root length and root DM as compared with UT seeds under WS as well as WW conditions. Root length of SMF-treated seeds was enhanced by $48,55,59$, and $45 \%$ at VS, FS, PLS, and PFS conditions, respectively (Fig. 1C). Root DM was also enhanced by $38,47,56$, and $41 \%$ in SMF-treated seeds at VS, FS, PLS, and PFS, respectively, as compared with UT seeds (Fig. 1D).

Pigment content: Enhancement in Chl contents was observed in plants that emerged from SMF-treated seeds under WS conditions as well as WW conditions. The SMF treatment enhanced the total $\mathrm{Chl}$ content by $40 \%$ at FS as compared with UT seeds under WW conditions (Fig. 2C). This enhancement at FS in the content of total $\mathrm{Chl}$ occurred due to the greater increase in $\mathrm{Chl} b$ by $82 \%$ rather than due to Chl $a(25 \%)$ (Fig. $2 A, B)$.

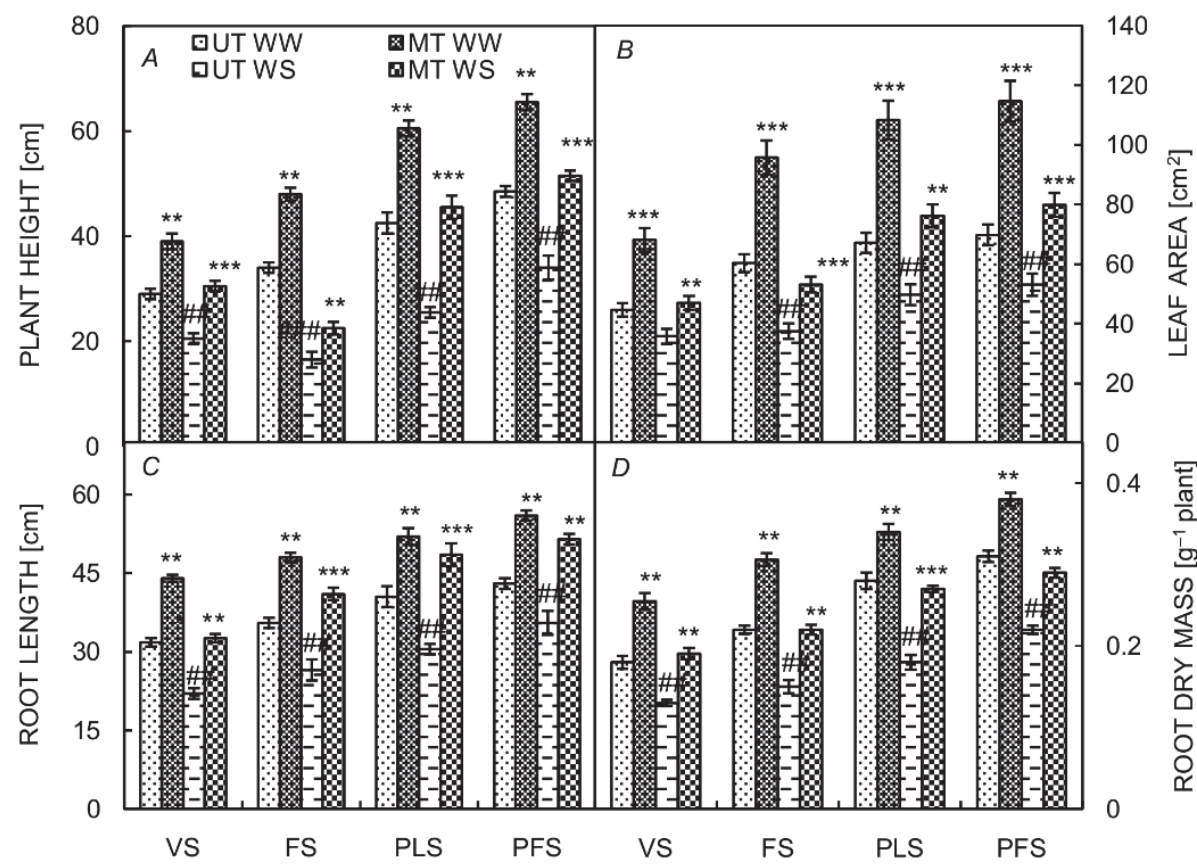

Fig. 1. Impact of prior-sowing exposure of soybean seeds to static magnetic field (200 $\mathrm{mT}$ for $1 \mathrm{~h})$ on plant height $(A)$, leaf area $(B)$, root length $(C)$, and root dry mass $(D)$ under water stress at different stages [vegetative stage (VS), flowering stage (FS), pod-lengthening stage (PLS), and pod-filling stage (PFS)]. The vertical bar indicates \pm SE for mean analyzed by the Student's $t$-test: ${ }^{\# \#} p<0.001$; ${ }^{\#} p<0.01$; ${ }^{\#} p<0.05$ denote significant differences between well watered control with water stress given at different growth stages of soybean plants that emerged from untreated seeds and ${ }^{* * *} p<0.001 ;{ }^{* *} p<0.01 ;{ }^{*} p<0.05$ denote statistically significant differences between SMFpretreated and untreated seedlings grown under the same stage of water stress in well-watered as well as water-stress conditions. 


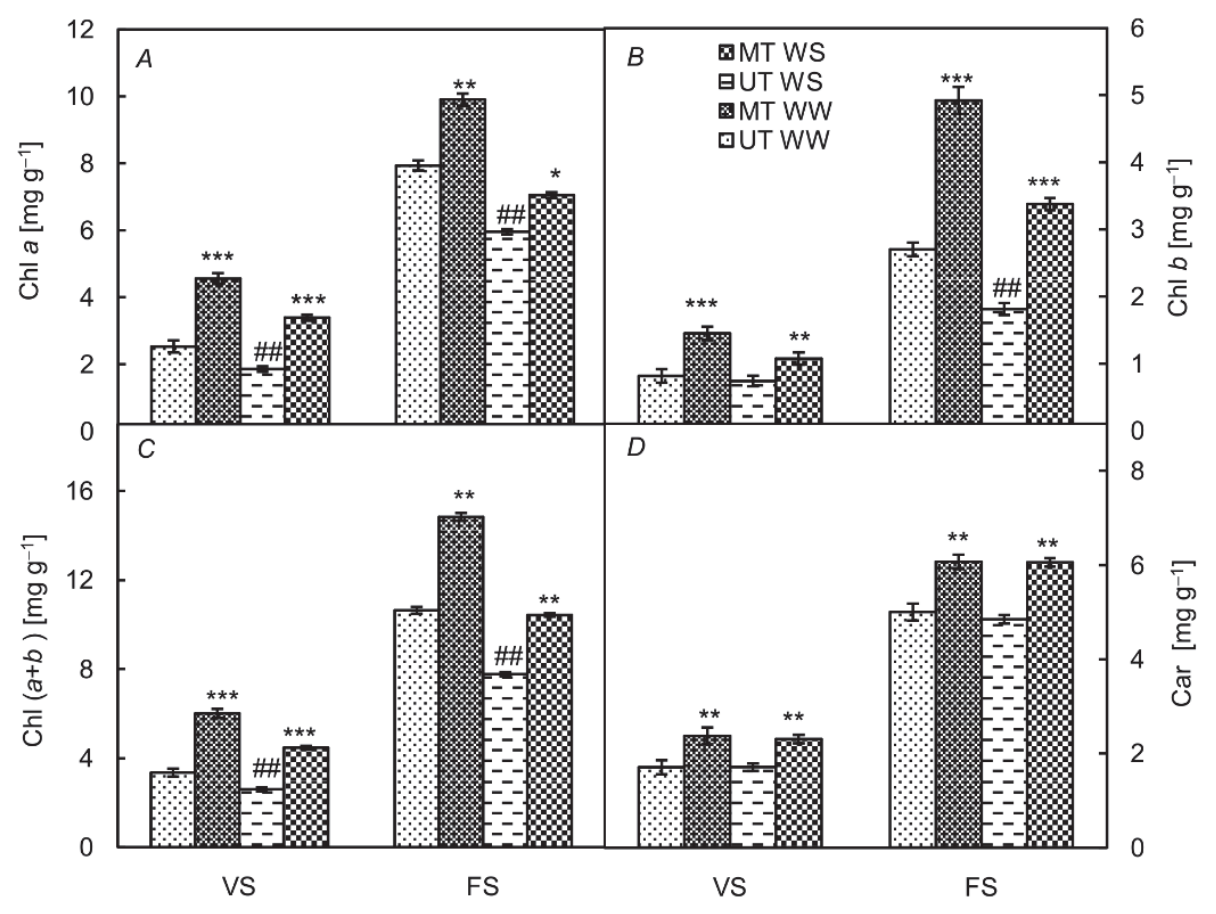

Fig. 2. Impact of prior-sowing exposure of soybean seeds to static magnetic field (200 mT for $1 \mathrm{~h})$ on chlorophyll (Chl) $a(A)$, Chl $b$ $(B)$, total Chl $(C)$, and total carotenoids (Car, $D)$ under water stress at VS and FS on $30 \mathrm{~d}$ after emergence (DAE) and 40 DAE, respectively. The vertical bar indicates \pm SE for mean analyzed by the Student's $t$-test. ${ }^{\# \#} p<0.001$; ${ }^{\# \#} p<0.01$; ${ }^{\#} p<0.05$ denote significant differences between control and water stress given at different growth stages of soybean plants that emerged from untreated seeds and ${ }^{* * *} p<0.001 ;{ }^{* * *} p<0.01 ;{ }^{*} p<0.05$ denote statistically significant differences between SMF-pretreated and untreated seedlings grown under the same stage of water stress in well-watered as well as water-stress conditions.

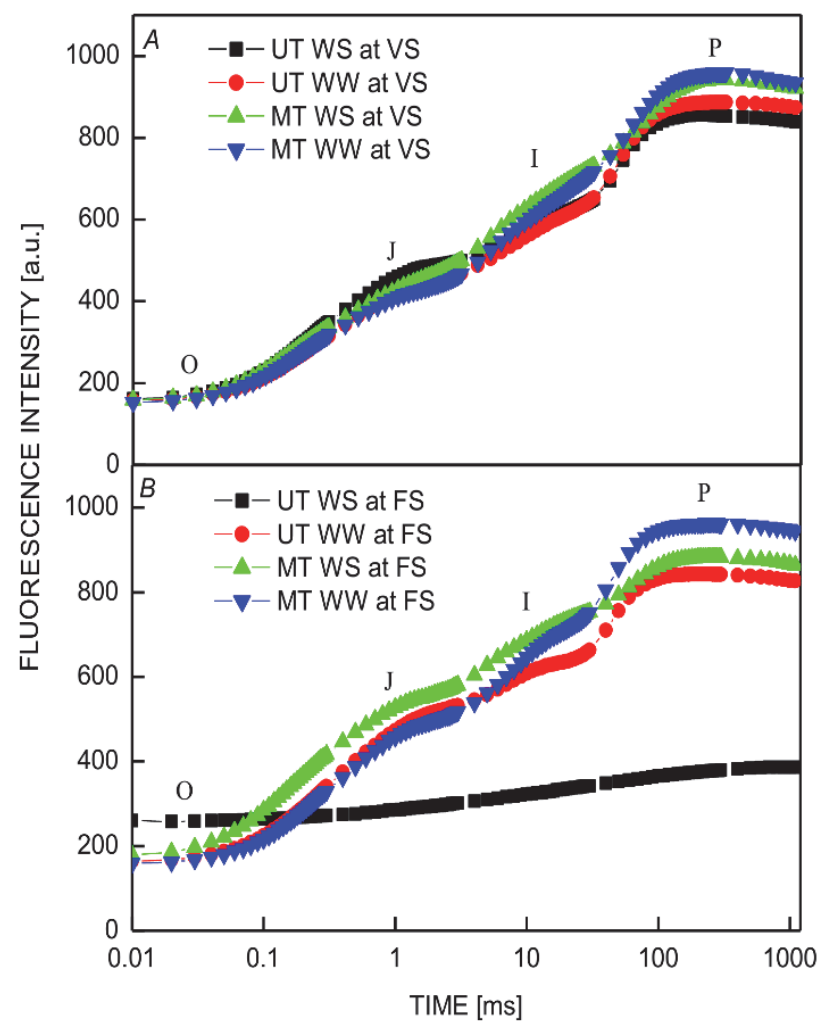

Fig. 3. Changes in polyphasic chlorophyll $a$ fluorescence $(\mathrm{O}-\mathrm{J}-\mathrm{I}-\mathrm{P})$ transient curves in soybean leaves from untreated seeds and after pretreatment of seeds with static magnetic field $(200 \mathrm{mT}$ for $1 \mathrm{~h}$ ) under water stress at VS on $30 \mathrm{~d}$ after emergence $(\mathrm{DAE})(A)$ and FS on 40 DAE $(B)$. (O-J-I-P are fluorescence yield at $20 \mu \mathrm{s}, 2 \mathrm{~ms}, 30 \mathrm{~ms}$, and maximum fluorescence, respectively).

Under WS conditions SMF treatment showed $72 \%$ promotion at VS and 34\% promotion at FS in total Chl as compared with UT plants. The same trend was obtained in Car; after SMF treatment, 39\% promotion was found when WS was given at VS on 30 DAE and $25 \%$ promotion was found when WS was given at FS on 40 DAE (Fig. 2D).

Chl $\boldsymbol{a}$ fluorescence: Polyphasic Chl $a$ fluorescence transient was measured to evaluate the effect of presowing exposure of SMF on photochemical efficiency of PSII under water stress conditions. The time course of fluorescence yield in dark-adapted intact leaves of soybean was plotted on logarithmic time scale (Fig. $3 A, B$ ); it clearly showed the separation of $\mathrm{O}-\mathrm{J}-\mathrm{I}-\mathrm{P}$ phase in plants emerged from UT and SMF-treated seeds under WW and WS at VS on 30 DAE (Fig. 3A). However, the O-J-I-P phase was not at all distinguished when water stress was given at FS on $40 \mathrm{DAE}$ in leaves of soybean plants emerged from 


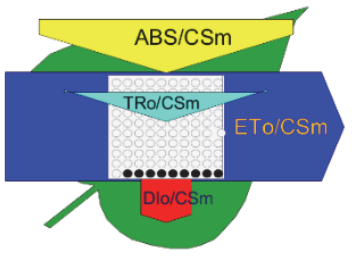

UT WW

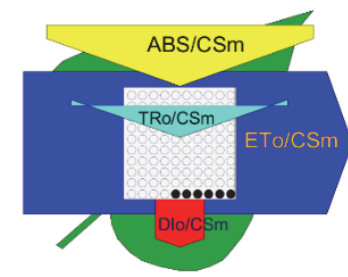

MT WW

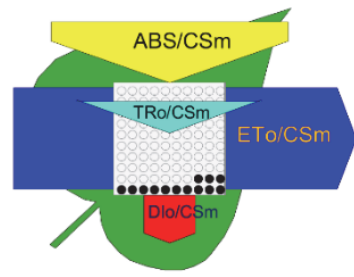

UT WS

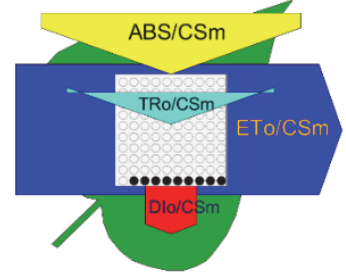

MT WS

A Water stress given at Vegetative Stages [VS] on 30 DAE

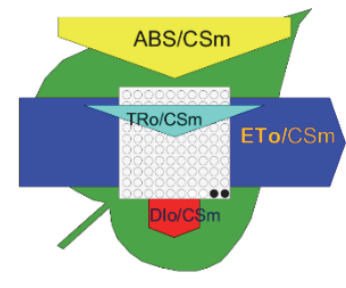

UT WW

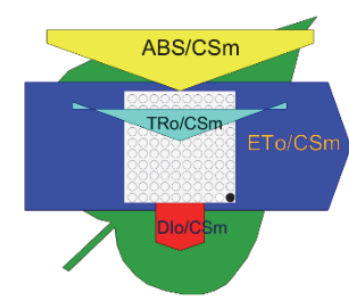

MT WW

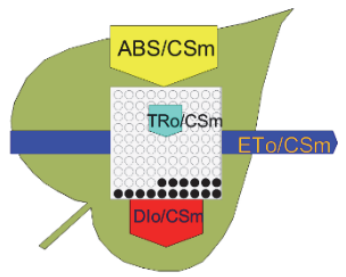

UT WS

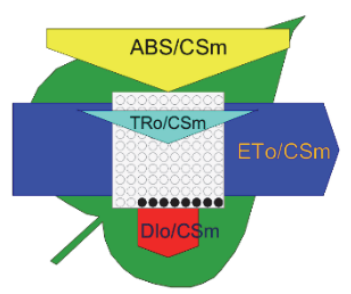

MT WS

$B$ Water stress given at Flowering Stage $[\mathrm{FS}]$ on $40 \mathrm{DAE}$

Fig. 4. Leaf model showing phenomenological energy fluxes per excited cross section (CS) of soybean leaves from untreated seeds $(A)$ and after pretreatment with static magnetic field $(200 \mathrm{mT}$ for $1 \mathrm{~h})(B) . \mathrm{ABS} / \mathrm{CS}_{\mathrm{m}}$ - absorption flux per CS, approximately $\mathrm{F}_{\mathrm{m}}$; TR $\mathrm{TR}_{\mathrm{o}} / \mathrm{CSM}$ - trapped energy per CS; $\mathrm{ET}_{\mathrm{o}} / \mathrm{CS}_{\mathrm{m}}$ - electron transport flux per CS; $\mathrm{DI} / \mathrm{CSM}$ - dissipated energy per CS. Each relative value is represented by the size of the proper parameters (arrow), empty circles represent reducing $\mathrm{Q}_{\mathrm{A}}$ reaction centres (active), full circles represent nonreducing $Q_{A}$ reaction centres (inactive or silent).

UT seeds (Fig. 3B). While at the same stage of WS, the damage was very small in the plants emerged from SMFtreated seeds (Fig. 3B) as compared with the plants emerged from UT seeds. Thus, fluorescence yield at J, I, and $\mathrm{P}$ phase increased in the plants emerged from SMFtreated seeds as compared with the plants emerged from UT seeds under WS at FS on 40 DAE (Fig. 3B).

A phenomenological leaf model generated by Biolyzer HP 3 software depicted more active reaction centers per unit of area of the leaf in the plants after SMF treatment. In this model, open circles represent the active reaction center; the plants after SMF treatment had more active reaction centers combined with higher efficiency of electron transport indicated by broader width of the arrow in the leaf models under WW as well as WS at VS and FS (Fig. 4A,B).

The maximal quantum efficiency of PSII (calculated from $\mathrm{F}_{\mathrm{v}} / \mathrm{F}_{\mathrm{m}}$ ) was only marginally decreased at VS (Fig. $5 A$ ), while it was drastically reduced when the WS was given at FS on 40 DAE (Fig. $5 A$ ). The $\mathrm{F}_{\mathrm{v}} / \mathrm{F}_{\mathrm{m}}$ did not show any significant difference between SMF-treated plants and UT plants in WW as well as WS conditions at VS (Fig. 5A). On the other hand, the SMF-treated plants recovered from WS as it was shown by significant increase in $\mathrm{F}_{\mathrm{v}} / \mathrm{F}_{\mathrm{m}}$ as compared with UT plants under WS at VS and FS (Fig. 5A).

Under WS, the electron transport per leaf CS $\left(\mathrm{ET}_{\mathrm{o}} /\right.$ $\mathrm{CS}_{\mathrm{m}}$ ) decreased more at FS in leaves of UT plants, while
SMF treatment caused significant promotion of $43 \%$ at FS (Fig. 5B). The $\mathrm{PI}_{\mathrm{abs}}$, which is an indicator of sample vitality, decreased drastically by $78 \%$ when WS was given at FS in leaves of the plants, which emerged from UT seeds (Fig. 5C). $\mathrm{PI}_{\mathrm{abs}}$ was significantly enhanced by SMF treatment; the enhancement of $189 \%$ was found under WS given at FS as compared with UT plants (Fig. 5C).

Leaf gas exchange: The $P_{\mathrm{N}}, g_{\mathrm{s}}$, and $E$ in SMF-treated plants were repeatedly higher in comparison to UT plants in WW as well as WS conditions at VS and FS (Fig. 6A$C)$. $C_{\mathrm{i}}$ was found to be slightly higher in the plants from UT seeds as compared to SMF-treated seeds (Fig. 6D).

An increase of 51 and $49 \%$ (VS and FS, respectively) in $P_{\mathrm{N}}$ and 38 and $50 \%$ enhancement in $g_{\mathrm{s}}$ (VS and FS, respectively) was recorded in the plants that emerged from SMF-treated seeds as compared with UT seeds in WW conditions (Fig. 6A,B). WS reduced these parameters as compared to WW conditions. WS given at VS caused 82 and $62 \%$ reduction in $P_{\mathrm{N}}$ at VS and FS, respectively, as compared with WW conditions (Fig. 6A).

The SMF treatment caused 38 and $92 \%$ in $P_{\mathrm{N}}, 29$ and $81 \%$ enhancement in $g_{\mathrm{s}}$, and 35 and $26 \%$ enhancement in $E$ under WS conditions at VS and FS conditions, respectively, as compared to their UT plants under WW (Fig. 6A-C). However, the SMF treatment caused a slight reduction of 12 and $16 \%$ in $C_{\mathrm{i}}$ at VS and FS stage, respectively, as compared with UT plants (Fig. 6D). 


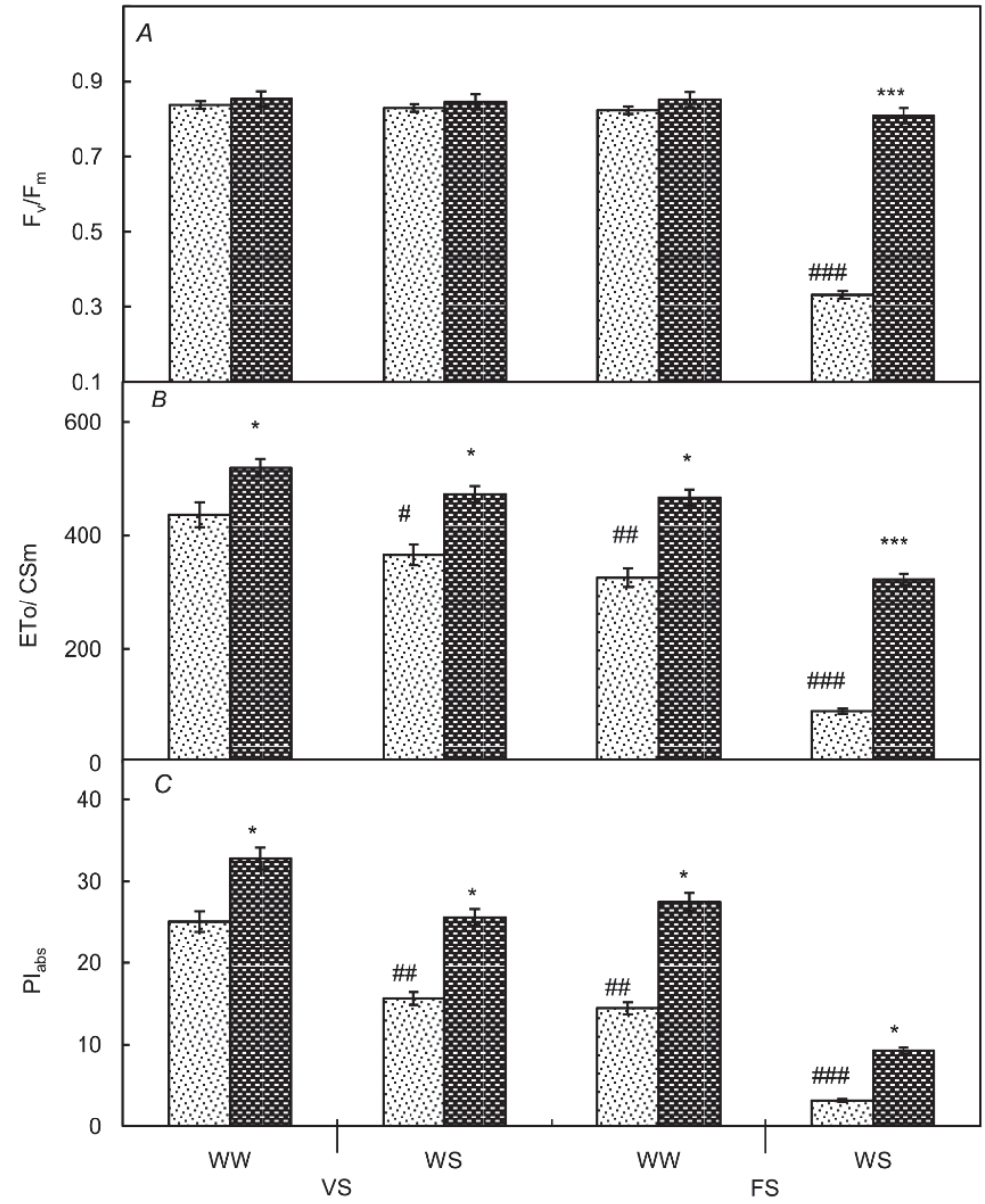

Fig. 5. Impact of prior-sowing exposure of soybean seeds to static magnetic field (SMF) $(200 \mathrm{mT}$ for $1 \mathrm{~h})$ on $\mathrm{F}_{\mathrm{v}} / \mathrm{F}_{\mathrm{m}}(A), \mathrm{ET}_{\mathrm{o}} / \mathrm{CS}_{\mathrm{m}}(B)$, and $\mathrm{PI}_{\text {abs }}(C)$ under water stress at VS on $30 \mathrm{~d}$ after emergence (DAE) and FS on $40 \mathrm{DAE}$. The vertical bar indicates $\pm \mathrm{SE}$ for mean analyzed by the Student's $t$-test: ${ }^{\# \# \#} p<0.001$; $\# p<0.01$; \# $p<0.05$ denote significant differences between control and water stress given at different growth stages of soybean plants that emerged from untreated seeds and ${ }^{* * *} p<0.001 ;{ }^{* *} p<0.01 ;{ }^{*} p<0.05$ denote statistically significant differences between SMF-pretreated and untreated seedlings grown under the same stage of water stress in well-watered as well as water-stress conditions.

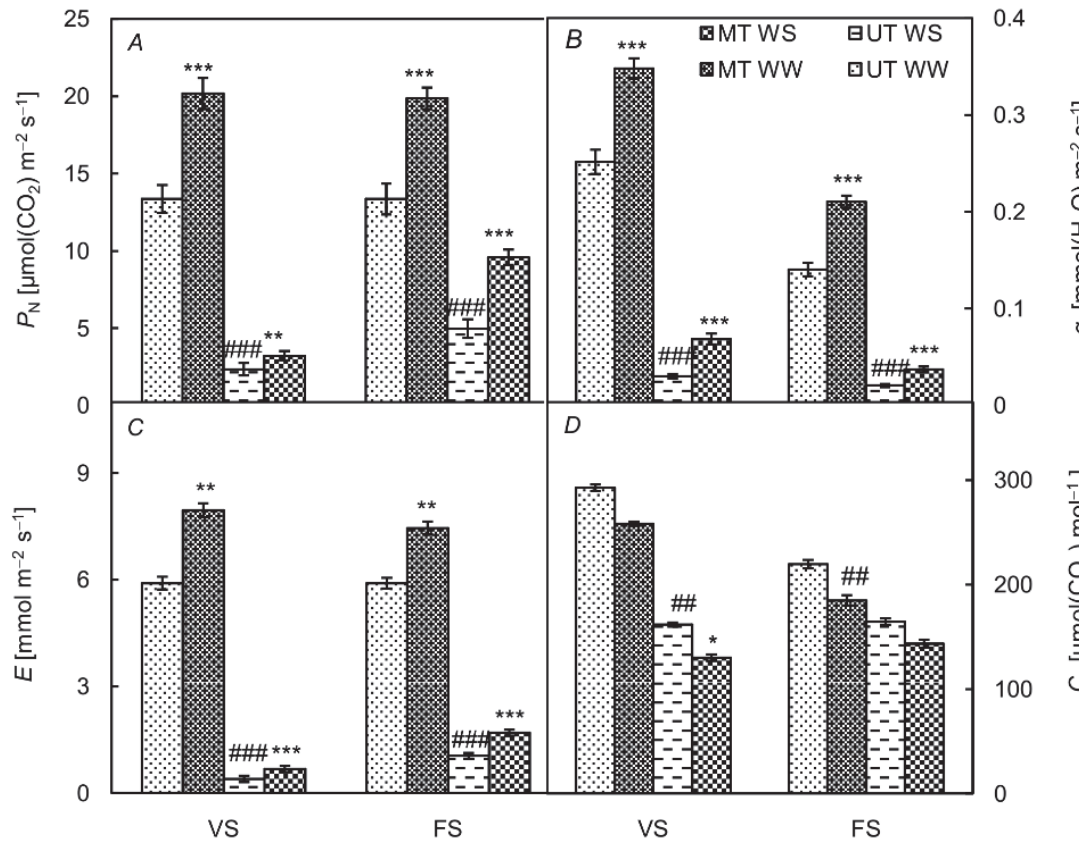

Fig. 6. Impact of prior-sowing exposure of soybean seeds to static magnetic field (SMF) $(200 \mathrm{mT}$ for $1 \mathrm{~h})$ on net photosynthetic rate $\left(P_{\mathrm{N}}, A\right)$, stomatal conductance $\left(g_{\mathrm{s}}, B\right)$, transpiration rate $(E, C)$, and intracellular $\mathrm{CO}_{2}$ concentration $\left(C_{\mathrm{i}}, D\right)$ under water stress at VS on $30 \mathrm{~d}$ after emergence (DAE) and FS on 40 DAE. The vertical bar indicates $\pm \mathrm{SE}$ for mean analyzed by the Student's t-test: ${ }^{\# \#} p<0.001$; \# $p<0.01$; \# $p<0.05$ denote significant differences between control and water stress given at different growth stages of soybean plants that emerged from untreated seeds and ${ }^{* * *} p<0.001 ;{ }^{* *} p<0.01 ;{ }^{*} p<0.05$ denote statistically significant differences between SMFpretreated and untreated seedlings grown under the same stage of water stress in wellwatered as well as water-stress conditions. 


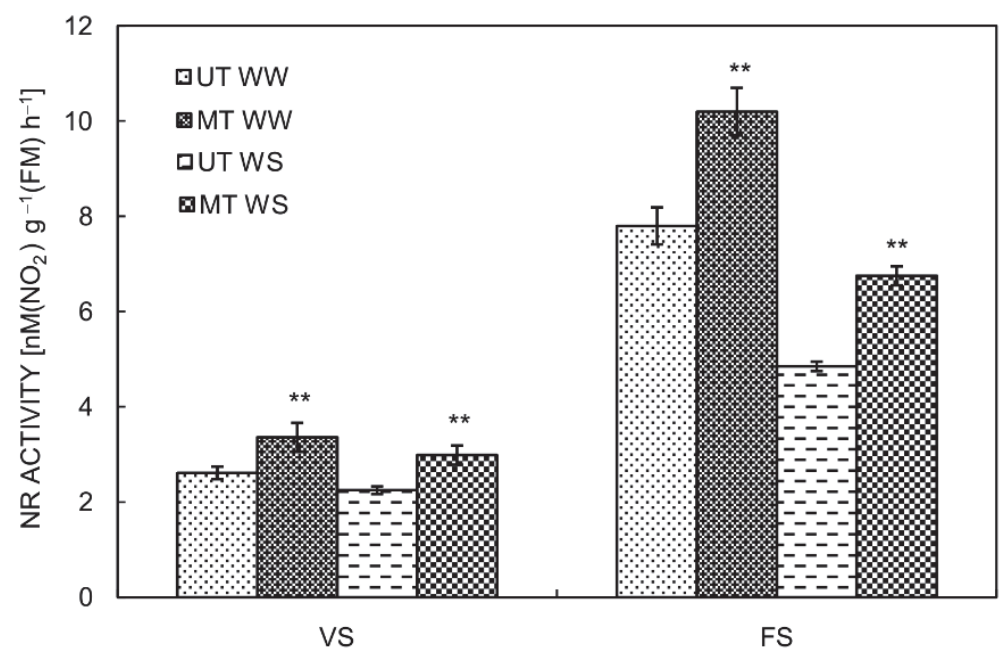

Fig. 7. Impact of prior-sowing exposure of soybean seeds to static magnetic field (SMF) (200 $\mathrm{mT}$ for $1 \mathrm{~h}$ ) on NR activity under water stress at VS on $30 \mathrm{~d}$ after emergence (DAE) and FS on 40 DAE. The vertical bar indicates \pm SE for mean analyzed by the Student's $t$ test: ${ }^{\# \#} p<0.001 ;{ }^{\#} p<0.01 ;{ }^{\#} p<0.05$ denote significant differences between control and water stress given at different growth stages of soybean plants that emerged from untreated seeds and ${ }^{* * *} p<0.001 ;{ }^{* *} p<0.01 ;{ }^{*} p<0.05$ denote statistically significant differences between SMF-pretreated and untreated seedlings grown under the same stage of water stress in well-watered as well as water stress conditions.

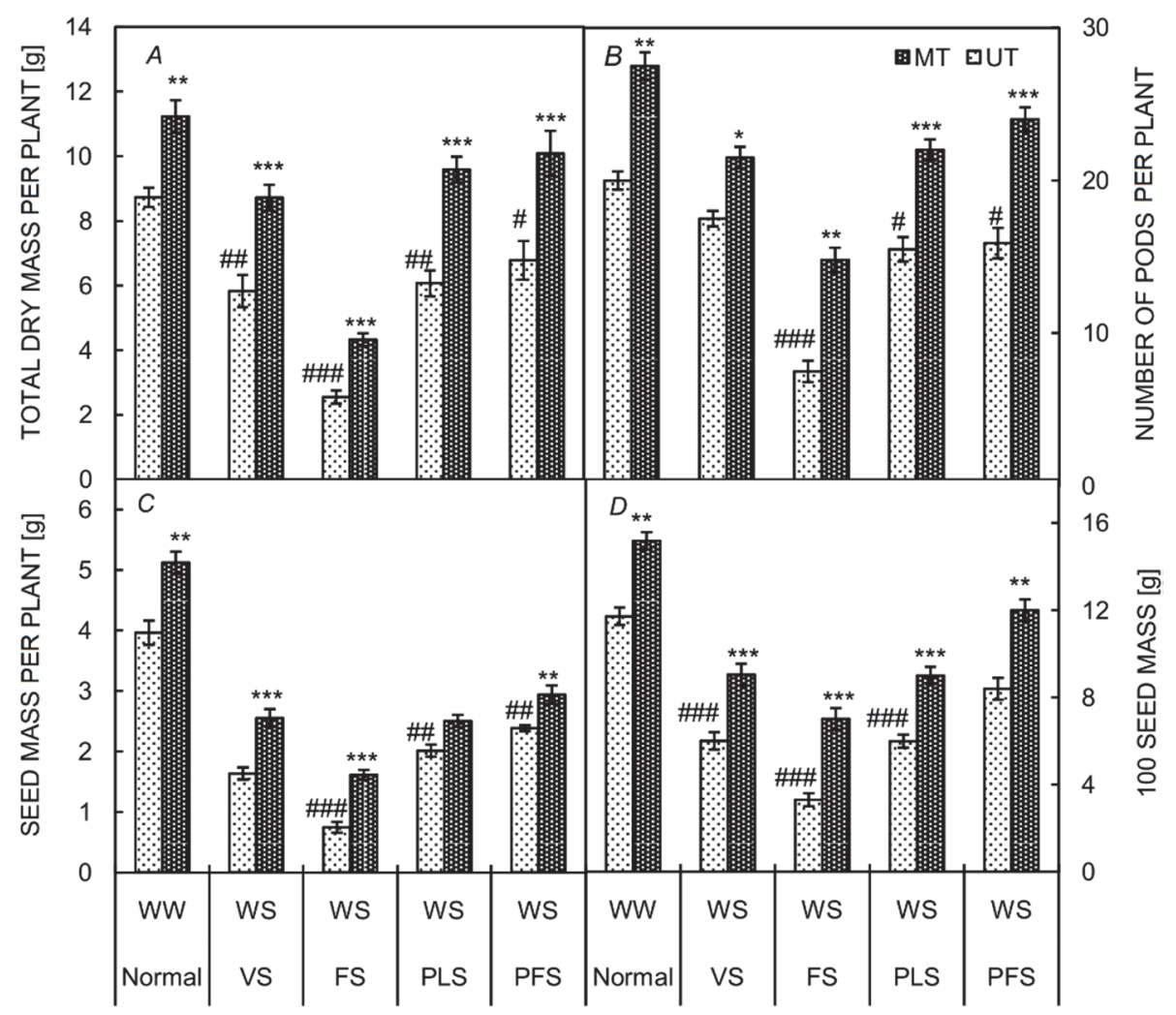

Fig. 8. Effect of prior-sowing exposure of soybean seeds to static magnetic field (SMF) (200 $\mathrm{mT}$ for $1 \mathrm{~h})$ on total dry mass [vegetative stage (VS), flowering stage (FS), pod-lengthening stage (PLS), and pod-filling stage (PFS)]. The vertical bar indicates \pm SE for mean analyzed by the Student's $t$-test: ${ }^{\# \#} p<0.001$; \# $p<0.01$; \# $p<0.05$ denote significant differences between control and water stress given at different growth stages of soybean plants that emerged from untreated seeds and ${ }^{* * *} p<0.001 ;{ }^{* *} p<0.01 ;{ }^{*} p<0.05$ denote statistically significant differences between SMF-pretreated and untreated seedlings grown under the same stage of water stress in well-watered as well as water-stress conditions. 
NR activity and yield: NR activity was measured in the leaves of soybean, when water stress was given at VS on 30 and FS on 40 DAE. Plants emerged from UT seeds showed lower NR activity which was significantly decreased (38\%) under WS at FS, whereas the plants that emerged from SMF-treated seeds showed higher NR activity under WS as well as under WW conditions (Fig. 7). Plants emerged from SMF-treated seeds showed 29 and $31 \%$ increase in NR activity under WS given at VS on 30 and at FS on 40 DAE, respectively, as compared to their UT counterparts at both the stages (Fig. 7).

All the yield parameters, such as number of pods, number of seeds per plant, seed mass per plant, 100-seed mass, and total DM, were significantly reduced under WS conditions given at all the stages (VS, FS, PLS, and PFS) in soybean plants from UT seeds (Fig. 8), while the plants

\section{Discussion}

Water stress is an important environmental factor that could influence the physiological and biochemical characteristics of plants (Ren et al. 2007). Water stress retards the growth and metabolic activity in soybean genotypes (Sepanlo et al. 2014, Khan et al. 2016). Our results also showed that water stress given at different growth stages (VS, FS, PLS, and PFS) caused reduction in growth, photosynthetic efficiency, and yield; it was also observed when the water stress was given at FS stage on 40 DAE - then it caused severe inhibitory effects on growth and yield of soybean. The effect of water deficit during reproductive growth was more pronounced than that during vegetative growth in rapeseed (Ghobadi et al. 2006). The inhibitory effect of the drought stress was reported on the rate of photosynthesis, growth, and particularly the seed yield of soybean plants was severely affected (Heidarzade et al. 2016).

Result of the present study indicated a positive impact of SMF of $200 \mathrm{mT}$ for $1 \mathrm{~h}$ on plant growth, PSII efficiency, photosynthesis, nitrogen metabolism, and yield under WW as well as WS conditions. The positive effect of SMF on the germination, growth, and yield of soybean was clearly evident under both normal and saline conditions (Thomas et al. 2013, Baghel et al. 2016). Under WS conditions, magnetic field treatment induced growth improvement in chickpea (Vashisth and Nagarajan 2010) and maize (Javed et al. 2011, Anand et al. 2012). However, nitrogen metabolism and yield attributes along with photosynthetic performance were not explored in the earlier studies on the effect of magnetic field under drought stress in maize seedlings (Javed et al. 2011, Anand et al. 2012).

In the present study, $\mathrm{Chl} a, \mathrm{Chl} b$, and total $\mathrm{Chl}$ decreased under water stress in all developmental stages in accordance with Loggini et al. (1999), Younis et al. (2000), and Elsheery and Cao (2008). Considerable reduction in $\mathrm{Chl}$ content due to water deficit was reported in some crop species (Ashraf et al. 1994, Garg et al. 1998). The decrease in Chl under drought stress occurred mainly from SMF pretreatment showed a significant enhancement in all of these parameters under WS as well as WW conditions (Fig. 8).

The enhancement in number of pods by SMF treatment was $23,97,42$, and $51 \%$ as compared with UT at VS, FS, PLS, and PFS stages of WS, respectively (Fig. 8B). Promotion recorded in seed mass per plant by SMF treatments was $56,116,24$, and $23 \%$, respectively, at VS, FS, PLS, and PFS stages of WS as compared with UT controls (Fig. 8C). The enhancement in a 100-seed mass by SMF treatment was $50,112,50$, and $43 \%$ compared with UT control at VS, FS, PLS and PFS stages of WS, respectively (Fig. 8D). Similarly, total DM (above- and belowground parts of plants) was enhanced by SMF treatment as compared with UT under WS as well as WW conditions (Fig. 8A).

because of damage to chloroplasts by active oxygen species (Smirnoff 1995). Our data also showed that the total Chl content was enhanced in leaves of soybean plants emerged from SMF treatment under WW as well as WS conditions (at VS and FS). Chl $b$ significantly increased, while Chl $a$ increased to a lesser extent in plants emerged after SMF pretreatment. Similarly, SMF treatment enhanced $\mathrm{Chl}$ content in soybean and maize leaves (Kataria et al. 2015, Baghel et al. 2016)

Chl $a$ fluorescence kinetics is an informative tool for studying the effects of different environmental stresses on photosynthesis (Kalaji et al. 2016). The JIP test gives adequate information about the structure, conformation, and function of the photosynthetic apparatus. Since shape changes in $\mathrm{O}-\mathrm{J}-\mathrm{I}-\mathrm{P}$ fluorescence transients can be translated to quantitative changes of several parameters, JIP parameters are very useful for in vivo investigation of photosynthetic apparatus, especially of PSII (Strasser et al. 2004). The time course of fluorescence yield in darkadapted intact third trifoliate leaves (under WW and WS conditions at VS and FS) plotted on logarithmic time scale showed the separation of $\mathrm{O}-\mathrm{J}-\mathrm{I}-\mathrm{P}$ phase (Fig. 3A,B). Polyphasic Chl $a$ fluorescence (O-J-I-P ) transients of the leaves in plants emerged from SMF treatment gave a higher fluorescence yield at I and P phase when the WS was given at FS stage as compared with the plants emerged from untreated seeds (Fig. $3 B$ ). The J step represents the momentary maximum of $\mathrm{Q}^{-}$, and $\mathrm{I}$ is suggested to be related to a heterogeneity in the filling up of the plastoquinone pool (Govindjee 1995, Strasser et al. 1995). The I-P phase seems to be related to the content of PSI reaction centers (Ceppi et al. 2012). However, a close link between PSI kinetics and the OJIP rise can also be explained on the basis of the PSII conformational change hypothesis (Schansker et al. 2014).

Results on Chl $a$ fluorescence reported in present study revealed that leaves of soybean plants that emerged from UT seeds under WS (both at VS and FS) showed lower 
efficiency of electron transport per cross section of leaf with higher inactive reaction centers, while on other hand, plants emerged from SMF-treated seeds had higher reducing power with higher efficiency of electron transport and more active reaction centers under WS conditions at VS and FS as well as WW conditions. Lazár et al. (2013) found that exogenous melatonin increased quantum yield of photochemistry of PSII due to the amount of open reaction centres of PSII and suggested that more open reaction centres reflect better functionality of all photosynthetic transport chain constituents.

Pretreatment of corn seeds with different electromagnetic treatments, particularly by 100 and $150 \mathrm{mT}$ for $10 \mathrm{~min}$, significantly alleviated the drought-induced adverse effects on growth by improving efficiency of PSII, $P_{\mathrm{N}}, E$, and $g_{\mathrm{s}}$ (Javed et al. 2011). In a similar experiment under greenhouse conditions, it was found that photosynthesis, $g_{\mathrm{s}}$, and $\mathrm{Chl}$ content increased in maize plants exposed to SMFs of $100 \mathrm{mT}$ for $2 \mathrm{~h}$ and $200 \mathrm{mT}$ for $1 \mathrm{~h}$, compared with control under irrigated and mild-stress conditions (Anand et al. 2012). The present study differs from these previous studies on effect of SMF treatment under water stress (Javed et al. 2011), because here the water stress was given at different growth stages of soybean (VS, FS, PLS, PFS), contrary to corn seedlings, where water stress was given at one stage only. O-J-I-P transient curves and JIP-test are the key indicators for studying the response of plants to environmental stress. In our results, drought stress at FS stage in particular changed the characteristic sites of the $\mathrm{O}-\mathrm{J}-\mathrm{I}-\mathrm{P}$ transient and reduced the flourescence intensity. Meng et al. (2016) reported that drought stress considerably decreased the fluorescence characteristics of PSII in leaves of Plectranthus scutellarioides via inhibition of electron transport and decrease of PSII photochemical activity. The parameters, which were affected most by water and salt stress, were the time needed to reach the maximal $\mathrm{Chl}$ fluorescence $\left(\mathrm{F}_{\mathrm{m}}\right)$, and the $\mathrm{F}_{\mathrm{v}} / \mathrm{F}_{\mathrm{o}}$, and $\mathrm{PI}_{\mathrm{abs}}$ (Kalaji et al. 2011, Meng et al. 2016).

Depending on the intensity and duration of water stress, metabolic limitations are frequently correlated with decrease in ATP (Parry et al. 2002). This reduction in ATP synthesis is due to the decrease in electron transport and photophosphorylation (Catuchi et al. 2011). The thylakoid membranes may suffer structural damage caused by decreasing the water content and ROS overproduction (Lawlor and Cornic 2002), reducing the efficiency of the photochemical apparatus.

In the present study, water stress at VS did not influence the $F_{v} / F_{m}$ measured in dark-adapted leaves of soybean, while water stress at FS drastically reduced the $\mathrm{F}_{\mathrm{v}} / \mathrm{F}_{\mathrm{m}}$. On the other hand, SMF pretreatment enhanced $\mathrm{F}_{\mathrm{v}} / \mathrm{F}_{\mathrm{m}}$ enormously under water stress at $\mathrm{FS}$ as compared with untreated controls. Plant vitality could be characterized by $\mathrm{PI}_{\mathrm{abs}}$ (Strasser et al. 2000). This integrative parameter includes three independent parameters: (1) density of fully active reaction centers (RCs); (2) efficiency of electron movement by trapped exciton into the electron transport chain beyond the $\mathrm{Q}_{\mathrm{A}}$; and (3) the probability that an absorbed photon will be trapped by RCs. Strasser et al. (2004) reported that $\mathrm{PI}_{\mathrm{abs}}$ reflects the functionality of both PSI and PSII and gives the quantitative information on the current state of plant performance under stress conditions. In the present study, $\mathrm{PI}_{\text {abs }}$ significantly increased by the SMF treatment in the soybean plants grown under WW and WS conditions. PI is often found to be a very sensitive parameter in different crops (Strasser et al. 2004, Jiang et al. 2006, Christen et al. 2007, Baghel et al. 2016, Kataria et al. 2017), which is in accordance with our results achieved on soybean plants under water stress.

In the current study, water stress conditions significantly decreased the rate of photosynthesis and $g_{\mathrm{s}}$ of leaves at both the stages studied (VS and FS), while SMF treatment enhanced both under WS and WW conditions (Fig. 6). Water stress reduced the $g_{\mathrm{s}}$, limiting the entry of $\mathrm{CO}_{2}$ into the substomatal chambers and thus reducing the diffusion of carbon to the site of carboxylation, resulting in significant decreases in carbon assimilation ( $\mathrm{Yu}$ et al. 2004). Decreased $g_{\mathrm{s}}$ due to water stress was also observed in soybean leaves by Makbul et al. (2011).

$\mathrm{NR}$ is a key enzyme of $\mathrm{N}$ metabolism, which converts nitrate $\left(\mathrm{NO}_{3}^{-}\right)$into nitrite $\left(\mathrm{NO}_{2}^{-}\right)$on the metabolic pathway leading to the formation of amino acids (Cánovas et al. 2007). In the present study, SMF treatment led to an induction in NR activity in leaves of soybean plants when compared to the untreated controls. The extent of promotion was greater at FS stage and WS. Similarly, the NR activity increased in soybean plants grown under salinity stress by SMF treatment (Baghel et al. 2016). The increase in NR activity by SMF treatment in the present study may be due to the increase of ATP supply through the enhancement in the activity of PSII under WS as well as WW conditions.

In the present study, the plant height, leaf area, total dry mass accumulation, efficiency of PSII, and rate of photosynthesis was promoted by SMF treatment. Due to the enhanced rate of photosynthesis and NR activity the yield of soybean improved by SMF treatment. The increase in yield was measured in term of number of pods, seed mass, and 100 -seed mass.

Our results are in agreement with the earlier reports showing the increase in the yield of soybean by the SMF treatment under normal and salt stress conditions (Baghel et al. 2016). According to our results, water stress given at FS (40 DAE) severely decreased the number of pods, seed mass, and 100-seed mass as compared to the stress given at VS, PLS and PFS. Our data showed that if water limitation occurred during the critical stage of growth, especially, at the time of FS, then due to water deficiency, the seed yield of soybean was reduced drastically (81\%) as compared with WW controls. Heidarzade et al. (2016) also observed that reproductive stage was most sensitive to water limitation and resulted in high reduction in pod 
numbers and yield loss.

The flowering and pod-setting stages were found to be the most sensitive stages to water stress in chickpea (Nayyar et al. 2006) and soybean (Liu et al. 2003).

On the other hand, the plants emerged from SMF treatment showed enhancement of $116 \%$ in the grain yield of soybean as compared to the plants emerged from untreated seeds under water stress at FS stage. Thus, SMF treatment to the soybean seeds was effective in alleviating the harmful effect of water stress. Similarly Radhakrishnan et al. (2012) reported that pulsed magnetic field treatment of soybean alleviated the harmful effect of salinity on calli growth by improving primary and secondary metabolism under salt-stress conditions. Thomas et al. (2013) reported the activity of total amylase, protease, and dehydrogenase increased by magneto-priming under both nonsaline and saline conditions. The magneto-priming of dry seeds of soybean can ameliorate the harmful effects of salt and UV-B stress on growth and yield (Baghel et al. 2016, Kataria et al. 2017). Increased uptake of $\mathrm{Ca}^{2+}$ ions in rice seedlings grown from seeds exposed to pulsed magnetic fields were responsible for greater leaf growth and meristematic tissues in stems and roots (Saktheeswari and Subrahmanyam 1989). It appears that membraneassociated $\mathrm{Ca}^{2+}$ transport represents a crucial step at which magnetic fields could come into play (Çelik et al. 2009, da Silva and Dobránszki 2016).

Two mechanisms of magneto-reception are currently receiving attention: (I) the "radical-pair mechanism" consisting of modulation of singlet-triplet interconversion rates of a radical pair by weak magnetic fields, (2) the "ion cyclotron resonance" that revolves around the fact that ions should circulate in a plane perpendicular to an external magnetic field with their Lamor frequencies,

\section{References}

Anand A., Nagarajan S., Verma A. et al.: Pre-treatment of seeds with static magnetic field ameliorates soil water stress in seedlings of maize (Zea mays L.). - Indian J. Biochem. Biophys. 49: 63-70, 2012.

Ashraf M.Y., Azmi A.R., Khan A.H., Ala S.A.: Effect of water stress on total phenol, peroxidase activity and chlorophyll contents in wheat (Triticum aestivum L.). - Acta Physiol. Plant. 16: 185-191, 1994.

Baghel L., Kataria S., Guruprasad K. N.: Static magnetic field treatment of seeds improves carbon and nitrogen metabolism under salinity stress in soybean. - Bioelectromagnetics 37: 455-470, 2016.

Bertolli S. C., Rapchan G. L., Souza G. M.: Photosynthetic limitations caused by different rates of water-deficit induction in Glycine max and Vigna unguiculata. - Photosynthetica 50: 329-336, 2012.

Cánovas F.M., Avila C., Cantón F.R. et al.: Ammonium assimilation and amino acid metabolism in conifers. - J. Exp. Bot. 58: 2307-2318, 2007.

Catuchi T.A., Vítolo H.F., Bertolli S.S., Souza G.M.: Tolerance to water deficiency between two soybean cultivars: transgenic versus conventional. - Ciênc. Rural 31: 373-378, 2011. which can interfere with an alternating electromagnetic field (Galland and Pazur 2005, Maffei 2014, da Silva and Dobranszki 2016). Related to radical pair model, cryptochromes have recently been reported to supposedly participate in the magneto-reception of plants, serving as sensors since they can form radical pairs (Xu et al. 2014, Maffei 2014).

In summary, the water stress at each stage of the growth may lead to a reduction in the yield of soybean. Our data showed that when water stress occurred during the critical stage of growth, especially, at the time of FS, then the seed yield was reduced drastically due to water deficiency in soybean. Possible causes for more stressful influence at the reproductive stages are remobilization of nitrogen and carbohydrates from leaf to leaf with increasing age, degradation of chlorophyll and light harvesting complexes (Momeni 2010). We found the significant changes in morphological and physiological characteristics of soybean plants after pretreatment with SMF under water-deficit conditions, which underline the susceptibility of this crop to drought stress. Based on the present results, we can conclude that water stress retarded the growth, metabolic activity, and the yield of soybean, whereas SMF-treated seeds showed a significant promotion in all the studied parameters under wellwatered as well as water-stress conditions. SMF pretreatment to the soybean seeds $(200 \mathrm{mT}$ for $1 \mathrm{~h})$ significantly alleviated the water stress-induced adverse effects on growth, PSII efficiency, NR activity, $P_{\mathrm{N}}$, and yield of soybean. This study may help to understand some adaptive mechanisms developed by soybean genotypes and contribute to identify useful traits for soybean breeding programmes under abiotic stresses.

Çelik Ö., Büyükuslu N., Atak C., Rzakoulieva A.: Effects of magnetic field on activity of superoxide dismutase and catalase in Glycine max (L.) Merr. roots. - Polish J. Environ. Stud. 18: 175-182, 2009.

Ceppi M.G., Oukarroum A., Çicek N. et al.: The IP amplitude of the fluorescence rise OJIP is sensitive to changes in the photosystem I content of leaves: a study on plants exposed to magnesium and sulfate deficiencies, drought stress and salt stress. - Physiol. Plantarum 144: 277-288, 2012.

Chen Y.P., Li R., He J.M.: Magnetic field can alleviate toxicological effect induced by cadmium in mungbean seedlings. - Ecotoxicology 20: 760-769, 2011.

Christen D., Schönmann S., Jermini M. et al.: Characterization and early detection of grapevine (Vitis vinifera) stress responses to esca disease by in situ chlorophyll fluorescence and comparison with drought stress. - Environ. Exp. Bot. 60: 504-514, 2007.

da Silva J.A., Dobránszki J.: Magnetic fields: how is plant growth and development impacted. - Protoplasma 253: 231-248, 2016.

Elsheery N.I., Cao K.F.: Gas exchange, chlorophyll fluorescence, and osmotic adjustment in two mango cultivars under drought stress. - Acta Physiol. Plant. 30: 769-777, 2008. 
Friedman M., Brandon D.L.: Nutritional and health benefits of soy proteins. - J. Agr. Food Chem. 49: 1069-1086, 2001.

Galland P., Pazur A.: Magnetoreception in plants. - J. Plant Res. 118: 371-389, 2005.

Garg B.K., Vyas S.P., Kathju S., Lahiri A.N.: Influence of water deficit stress at various growth stages on some enzymes of nitrogen metabolism and yield in cluster bean genotypes. - J. Plant. Physiol. 3: 214-218, 1998.

Gerten D., Rost S.: Development and Climate Change: Climate Change Impacts on Agricultural Water Stress and Impact Mitigation Potential. Pp. 8. Potsdam Institute for Climate Impact Research (PIK), Potsdam 2010.

Ghobadi M.E., Nadian H., Bakhshandeh M. et al.: Study of root growth, biological yield and grain yield of wheat genotypes under water logging stress during different growth stages. Seed Plant Improv. J. 22: 513-527, 2006.

Govindjee.: Sixty-three years since Kautsky: Chlorophyll $a$ fluorescence. - Aust. J. Plant Physiol. 22: 131-160, 1995.

Heidarzade A., Esmaeili M., Bahmanyar M., Abbasi R.: Response of soybean (Glycine max) to molybdenum and iron spray under well-watered and water deficit conditions. - J. Exp. Biol. Agr. Sci. 4: 37-46, 2016.

Hiscox J.D., Israelstam G.F.: A method for the extraction of chlorophyll from leaf tissue without maceration. - Can. J. Bot. 57: 1332-1334, 1979.

Javed N., Ashraf M., Akram N., Al-Qurainy F.: Alleviation of adverse effects of drought stress on growth and some potential physiological attributes in maize (Zea mays) by seed electromagnetic treatment. - Photochem. Photobiol. 87: 1354$1362,2011$.

Jaworski E.G. : Nitrate reductase assay in intact plant tissue. Biochem. Biophys. Res. Co. 43: 1274-1279, 1971.

Jiang C.D., Shi L., Gao H.Y. et al.: Development of photosystems II and I during leaf growth in grapevine seedlings probed by chlorophyll $a$ fluorescence transient and $820 \mathrm{~nm}$ transmission in vivo. - Photosynthetica 44: 454-463, 2006.

Kalaji H.M., Govindjee, Bosa K. et al.: Effects of salt stress on photosystem II efficiency and $\mathrm{CO}_{2}$ assimilation of two Syrian barley landraces. - Environ. Exp. Bot. 73: 64-72, 2011.

Kalaji H.M., Jajoo A., Oukarroum A. et al.: Chlorophyll $a$ fluorescence as a tool to monitor physiological status of plants under abiotic stress conditions. - Acta Physiol. Plant. 38: 102, 2016.

Kataria S., Baghel L., Guruprasad K.N.: Effect of seed pretreatment by magnetic field on the sensitivity of maize seedlings to ambient ultraviolet radiation $(280-400 \mathrm{~nm})$. - Int. J. Trop. Agric. 33: 1-7, 2015.

Kataria S., Baghel L., Guruprasad K.N.: Alleviation of adverse effects of ambient uv stress on growth and some potential physiological attributes in soybean (Glycine max) by seed pretreatment with static magnetic field. - J. Plant Growth Regul. DOI: 10.1007/s00344-016-9657-3, 2017.

Khan M.S.A., Karim M.A., Haque M.M. et al.: Influence of salt and water stress on growth and yield of soybean genotypes. Pertanika J. Trop. Agri. Sci. 39: 167-180, 2016.

Krawiec A.C.L., Kaufman D.S., Vaillencourt D.A.: Age models and tephrostratigraphy from two lakes on Adak Island, Alaska. - Quat. Geochronol. 18: 41-53, 2013.

Lawlor D.W., Cornic G.: Photosynthetic carbon assimilation and associated metabolism in relation to water deficits in higher plants. - Plant Cell Environ. 25: 275-294, 2002.

Lazár D., Murch S.J., Beilby M.J., Al Khazaaly S.: Exogenous melatonin affects photosynthesis in characeae Chara australis.
- Plant Signal Behav. 8: e23279, 2013.

Lisar S.Y.S., Motafakkerazad R., Hossain M.M., Rahman, I.M.M.: Water stress in plants: causes, effects and responses. In: Rahman I.M.M., Hasegawa H. (ed.): Water Stress. Pp. 114. InTech, Rijeka 2012.

Liu F.L., Andersen M.N., Jacobsen S.E., Jensen C.R.: Stomatal control and water use efficiency of soybean (Glycine max L. Merr.) during progressive soil drying. - Environ. Exp. Bot. 54: 33-40, 2005.

Liu, F., Andersen M.N., Jensen C.R.: Loss of pod set caused by drought stress is associated with water status and ABA content of reproductive structures in soybean. - Funct. Plant Biol. 30: 271-280, 2003.

Loggini B., Scartazza A., Brugnoli E., Navari-Izzo F.: Antioxidative defense system, pigment composition, and photosynthetic efficiency in two wheat cultivars subjected to drought. - Plant Physiol. 119: 1091-1099, 1999.

Maffei M.E.: Magnetic field effects on plant growth, development and evolution. - Front. Plant Sci. 5: 445, 2014.

Mahajan T.S., Pandey O.P.: Magnetic-time model at off season germination. - Int. Agrophys. 28: 57-62, 2014.

Makbul S., Saruhan Güler N.S., Durmus N., Güven S.: Changes in anatomical and physiological parameters of soybean under drought stress. - Turk. J. Bot. 35: 369-377, 2011.

Manavalan L.P., Guttikonda S.K., Tran L.S.P., Nguyen H.T.: Physiological and molecular approaches to improve drought resistance in soybean. - Plant Cell Physiol. 50: 1260-1276, 2009.

Meng L.L., Song J.F., Wen J. et al.: Effects of drought stress on fluorescence characteristics of photosystem II in leaves of Plectranthus scutellarioides. - Photosynthetica 54: 414-421, 2016.

Momeni S.: Effect of seed priming with salicylic acid and polyethylene glycol in combination with salicylic acid spraying plants with drought resistance of maize (Zea mays L.). - Master Thesis. Seed Science and Technology University of Birjand, Birjand 2010.

Nayyar H., Singh S., Kaur, S. et al.: Differential sensitivity of macrocarpa and microcarpa types of chickpea (Cicer arietinum L.) to water stress: association of contrasting stress response with oxidative injury. - J. Integr. Plant Biol. 48: 1318-1329, 2006.

Parry M.A.J., Androlojc J.P., Khan S. et al.: Rubisco activity: efects of water stress. - Ann. Bot.-London 89: 833-839, 2002.

Passioura J.: The drought environment: physical, biological and agricultural perspectives. - J. Exp. Bot. 58: 113-117, 2007.

Pinheiro C., Chaves M.M.: Photosynthesis and drought: can we make metabolic connections from available data? - J. Exp. Bot. 62: 869-882, 2011.

Radhakrishnan R., Leelapriya T., Kumari B.D.: Effects of pulsed magnetic field treatment of soybean seeds on calli growth, cell damage and biochemical changes under salt stress. Bioelectromagnetics 33: 670-681, 2012.

Ren J., Dai W.R, Xuan Z.Y. et al:: The effect of drought and enhanced UV-B radiation on the growth and physiological traits of two contrasting poplar species. - Forest Ecol. Manage. 239: 112-119, 2007.

Ružič R., Jerman I.: Weak magnetic field decreases heat stress in cress seedlings. - Electromagn. Biol. Med. 21: 69-80, 2002.

Saktheeswari N., Subrahmanyam S.: Effects of pulsed magnetic field on histology, biochemistry and magnetotropism of paddy (Oryza sativa). - Bioelectromagn. Biomed. 2: 37-44, 1989.

Schansker G.,Tóth S.Z., Holzwarth A.R., Garab G.: Chlorophyll 
a fluorescence: beyond the limits of the $\mathrm{Q}_{\mathrm{A}}$ model. Photosynth. Res. 120: 43-58, 2014.

Sepanlo N., Talebi R., Rokhzadi A., Mohammadi H.: Morphological and physiological behavior in soybean (Glycine max) genotypes to drought stress implemented at pre- and postanthesis stages. - Acta Biol. Szeged. 58: 109-113, 2014.

Shan L., Zhang S.Q.: Is possible to save large irrigation water? The situation and prospect of water-saving agriculture in China. - Chin. J. Nature 28: 71-74, 2006.

Shao H.B., Chu L.Y., Jaleel C.A. et al.: Understanding water deficit stress-induced changes in the basic metabolism of higher plants- biotechnologically and sustainably improving agriculture and the eco environment in arid regions of the globe. - Crit. Rev. Biotechnol. 29: 131-151, 2009.

Shao H.B., Guo Q.J., Chu L.Y. et al.: Understanding molecular mechanism of higher plant plasticity under abiotic stress. Colloid Surface B 54: 37-45, 2007.

Shao H.B., Liang Z.S., Shao M.A.: Adaptation of higher plants to environmental stresses and stress signal transduction. - Acta Ecol. Sin. 25: 1871-1882, 2005.

Shine M.B., Guruprasad K.N., Anand A.: Enhancement of germination, growth and photosynthesis in soybean by pretreatment of seeds with magnetic field. - Bioelectromagnetics 32: 474-448, 2011.

Smirnoff N.: Antioxidant systems and plant response to the environment. - In: Smirnoff V. (ed.): Environment and Plant Metabolism: Flexibility and Acclimation, BIOS Scientific Publishers, Oxford 1995.

Strasser R.J., Srivastava A., Govindjee.: Polyphasic chlorophyll $a$ fluorescence transient in plants and cyanobacteria. Photochem. Photobiol. 61: 32-42, 1995.

Strasser R.J., Srivastava A., Tsimilli-Michael M.: The fluorescence transient as a tool to characterize and screen photosynthetic samples. - In: Yunus M., Pathre U., Mohanty P. (ed.): Probing Photosynthesis: Mechanisms, Regulation and Adap- tation. Pp. 445-483, Taylor and Francis Publ., London 2000.

Strasser R.J., Tsimilli-Michael M., Srivastava A: Analysis of the fluorescence transient. - In: Papageorgiou G.C., Govindjee (ed.): Chlorophyll Fluorescence: A Signature of Photosynthesis. Advances in Photosynthesis and Respiration Series. Pp. 321-362, Springer Publ., Dordrecht 2004.

Thomas S., Anand A., Chinnusamy V. et al:: Magnetopriming circumvents the effect of salinity stress on germination in chickpea seeds. - Acta Physiol. Plant. 35: 3401-3411, 2013.

Vashisth A., Nagarajan S.: Effect on germination and early growth characteristics in sunflower (Helianthus annus) seeds exposed to static magnetic field. - J. Plant Physiol. 167: 149$156,2010$.

Vashisth A., Nagarajan S.: Exposure of seeds to static magnetic field enhances germination and early growth characteristics in chickpea (Cicer arietinum L.). - Bioelectromagnetics 29: 571$578,2008$.

Wallace J.S.: Increasing agricultural water use efficiency to meet future food production. - Agr. Ecosyst. Environ. 82:105-119, 2000.

Wellburn A.R., Lichtenthaler H.: Formulae and programme to determine total carotenoids and chlorophyll $a$ and $b$ of leaf extracts in different solvents. - In: Sybesma C. (ed.): Advances in Photosynthesis Research. Pp. 12. Martinus Nijhoff/ Dr. W. Junk Publishers, Boston 1984.

Xu C., Lv Y., Chen C. et al.: Blue light-dependent phosphorylations of cryptochromes are affected by magnetic fields in Arabidopsis. - Adv. Space Res. 53: 1118-1124, 2014.

Younis M.E., El-Shahaby O.A., Abo-Hame S.A., Ibrahim A.H.: Effects of water stress on growth, pigments and ${ }^{14} \mathrm{CO}_{2}$ assimilation in three sorghum cultivars. - Agron. Crop Sci. 185: 73-82, 2000.

Yu Q., Zhang Y., Liu Y., Shi P.: Simulation of the stomatal conductance of winter wheat in response to light, temperature and $\mathrm{CO}_{2}$ changes. - Ann. Bot.-London 93: 435-441, 2004. 